\title{
relazioni
}

\section{SESSIONE 5}

\section{I disordini linfoproliferativi: ruolo eziopatogenetico di nuovi agenti infettivi}

Giovedi 13 ottobre 2005, ore 09.00 - 13.00, Sala E

\section{S5.1}

\section{PATOGENESI DEI DISORDINI LINFOPROLIFERATIVI AD EZIOLOGIA INFETTIVA}

\section{Dolcetti R.}

\section{U.O. Immunovirologia e Bioterapie, Dip. della Ricerca Preclinica ed Epidemiologica, Centro di Riferimento Oncologico, IRCCS - Istituto Nazionale Tumori, Aviano (PN).}

L'associazione tra disordini linfoproliferativi umani ed agenti infettivi è nota da tempo. Nella maggior parte dei casi tale associazione patogenetica è data da evidenze epidemiologiche e sperimentali che supportano un'azione trasformante diretta di agenti infettivi, prevalentemente di natura virale, quali EBV, HHV-8 e HTLV-I. Le forme più rappresentate sono quelle legate all'infezione da EBV e comprendono linfomi a carico di cellule B, T e NK, quali il linfoma di Burkitt endemico, le linfoproliferazioni associate all'immunodepressione, il linfoma di Hodgkin, i linfomi a cellule $\mathrm{T}$ periferiche e i linfomi nasali a cellule T/NK. In genere il genoma di tali virus è presente nella totalità delle cellule tumorali e consente l'espressione di proteine virali che contribuiscono direttamente all'induzione del fenotipo trasformato. Ciò si realizza grazie alla capacità di diverse proteine virali di interferire con vie di transduzione del segnale che controllano la proliferazione e la sopravvivenza delle cellule. Alcuni di questi virus, l'EBV in particolare, hanno inoltre evoluto una serie di meccanismi che impediscono il riconoscimento e l'eliminazione delle cellula infettate da parte del sistema immune dell'ospite. L'identificazione dei signalings intracellulari attivati da EBV, HHV-8 ed HTLV-I e la comprensione dei meccanismi di immunoevasione realizzati da tali virus si stanno rivelando utili per definire nuovi bersagli per strategie terapeuti- che sempre meno tossiche e più individualizzate.

Le conoscenze acquisite negli ultimi anni, tuttavia, hanno dimostrato come lo spettro di disordini linfoproliferativi umani associati ad agenti infettivi sia probabilmente più ampio di quanto inizialmente ipotizzato. Ciò riguarda prevalentemente disordini linfoproliferativi benigni o maligni nella cui patogenesi sarebbero implicate infezioni nella maggior parte dei casi di natura batterica: Helicobacter pylori, Campylobacter jejuni, Borrelia burgdorferi, Clamydiophila psittaci e Chlamydia pneumoniae. Tali agenti non agirebbero in modo trasformante diretto come i virus oncogeni "convenzionali", ma promuoverebbero l'induzione ed il mantenimento della linfoproliferazione infettando cellule presenti nel microambiente tumorale agendo come stimolo antigenico cronico. Un simile modello patogenetico è applicabile anche ai disordini linfoproliferativi associati all'infezione da HCV.

Tali acquisizioni hanno importanti ricadute pratiche sia per quanto riguarda le attività diagnostiche del Microbiologo Clinico che per le rilevanti implicazioni terapeutiche.

Ciò in particolare è testimoniato dalle significative risposte cliniche indotte dal trattamento con antibioticoterapia specifica in una significativa frazione di pazienti con linfomi associati a tali infezioni batteriche. 